\title{
Adenovírus e rotavírus em águas superficiais do córrego Ribeirão Preto, São Paulo, Brasil
}

\author{
Adenovirus and rotavirus in surface water of the Ribeirão Preto
} stream, São Paulo, Brazil

\author{
Jennifer Midiani Gonella* \\ Karina Aparecida de Abreu Tonani* \\ Brisa Maria Fregonesi* \\ Carolina Sampaio Machado* \\ Rudison Beltramini Trevilato* \\ Guilherme Sgobbi Zagui* \\ Renato Igor da Silva Alves* \\ Susana Inés Segura Munõz *
}

\begin{abstract}
Resumo
Com o desenvolvimento humano, os recursos hídricos sofrem modificações derivadas da expansão demográfica e principalmente da falta de saneamento básico, que interferem diretamente na qualidade desses recursos com a introdução de substâncias químicas tóxicas e bioagentes patogênicos. Os vírus entéricos de veiculação hídrica, como adenovírus e rotavírus, merecem destaque considerando seus impactos na saúde pública. O objetivo deste estudo foi avaliar a presença de adenovírus e rotavírus em águas superficiais do Córrego Ribeirão Preto, SP. A coleta foi realizada em 11 pontos distintos, da nascente até a confluência com o Rio Pardo. O Teste de ELISA foi o método utilizado para a detecção dos vírus (RIDASCREEN® Adenovirus, RIDASCREEN® Rotavirus - R-Biopharm). De acordo com os resultados obtidos, $73 \%$ das amostras foram positivas para adenovírus, enquanto que $36 \%$ foram positivas para rotavírus. Considerando a virulência desses vírus entéricos e a vulnerabilidade de indivíduos imunossuprimidos, idosos e crianças, é preocupante a contaminação por esses agentes patogênicos de veiculação hídrica amplamente disseminados em águas superficiais.
\end{abstract}

Palavras-chave: Água de Superfície. Adenovírus Humano. Rotavírus. Saúde Ambiental.

\begin{abstract}
Water resources have been suffering with the changes in demographic expansion and the lack of basic sanitation. These factors directly interfere with the quality of these resources due to the discharge of toxic chemicals and pathogenic bio-agents. The waterborne enteric viruses, such as rotavirus and adenovirus, deserve attention considering its impact on public health. The aim of this study was to evaluate the presence of adenovirus and rotavirus in surface water of Ribeirão Preto stream. Samplings were conducted in 11 different points from the spring to the confluence with the Rio

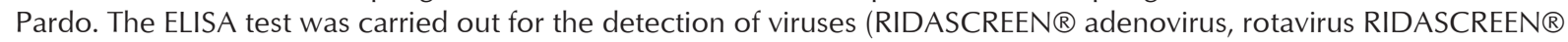
- R-Biopharm). According to the results, $73 \%$ of the samples were positive for adenovirus, while $36 \%$ were positive for rotavirus. Given the virulence of these enteric viruses and the vulnerability of immunosuppressed individuals, i.e. the elderly and children, contamination with these waterborne pathogens widely disseminated in surface water is concerning.
\end{abstract}

Keywords: Surface Waters. Adenoviruses Human. Rotavirus. Environmental Health

DOI: 10.15343/0104-7809.20164004474480

\footnotetext{
* Escola de Enfermagem de Ribeirão Preto da Universidade de São Paulo, Ribeirão Preto, SP, Brasil.

** Escola de Enfermagem de Ribeirão Preto da Universidade de São Paulo, Ribeirão Preto, SP, Brasil. E-mail: susis@eerp.usp.br.

Os autores declaram não haver conflitos de interesse.
} 


\section{INTRODUÇÃO}

O crescimento populacional e industrial observado nas últimas décadas atrelado às mudanças climáticas tem influenciado de maneira significativa os padrões de qualidade dos corpos hídricos ${ }^{1}$. A poluição das águas é ocasionada especialmente pelos resíduos domésticos, industriais e agrícolas, o que pode apresentar uma ameaça para saúde pública em virtude da exposição a substâncias químicas orgânicas e inorgânicas bem como a bioagentes potencialmente patogênicos ${ }^{2,3}$.

Segundo a Organização Mundial da Saúde estima-se que aproximadamente 2,2 milhões de pessoas morrem anualmente por problemas gastrointestinais, sendo que a grande maioria estão relacionados com a qualidade microbiológica da água ${ }^{4}$. Nesse contexto merecem destaque os vírus entéricos de veiculação hídrica.

Os vírus entéricos, são áqueles veiculados pela água, por meio da rota fecal-oral, com capacidade de infecção e replicação no trato gastrointestinal de seu hospedeiro, sendo posteriormente excretado nas fezes, como o adenovírus e o rotavírus. $\mathrm{O}$ adenovírus e o rotavírus se destacam entre os principais patógenos não bacterianos envolvidos nas gastroenterites, especialmente em crianças. Sabe-se, ainda, que em idosos e pessoas com o sistema imunológico suprimido estas infecções podem ser fatais. ${ }^{5,6}$.

Umas das grandes preocupações no contexto da saúde pública se deve à baixa dose de vírus entéricos necessária para causar infecção em hospedeiros humanos, bem como, a gravidade da morbidade em indivíduos imunossuprimidos, idosos e crianças ${ }^{7,8}$. Além disso, a disseminação de vírus entéricos em ambientes aquáticos localizados no espaço urbano é preocupante, considerando a persistência ambiental desses agentes e a resistência que apresentam a processos convencionais de tratamento de água e esgoto ${ }^{8,9}$.

Os vírus entéricos atingem as águas superficiais especialmente por meio do lançamento de efluentes domésticos e agropecuários, uma vez que, são eliminados em altas concentrações nas fezes de humanos e animais infectados ${ }^{10,11}$. Cabe destacar, que são escassos os estudos na literatura que relatam a presença de adenovírus e rotavírus em águas superficiais e subterrâneas bem como em esgoto bruto e tratado.

Embora o Brasil apresente uma situação privilegiada quanto à abundância dos recursos hídricos, há evidencias de que vem sofrendo uma diminuição da qualidade das águas devido às diversas ações antrópicas ${ }^{12}$. O córrego Ribeirão Preto é um recurso hídrico de água doce pertencente à classe 4, localizado na região de Ribeirão Preto, SP, cujo uso deveria se destinar à navegação e harmonia paisagística ${ }^{13}$. Entretanto, há constatações do uso indevido destas águas pela comunidade local ${ }^{14}$, o que representa um risco para a saúde humana, considerando possíveis descargas pontuais e difusas de efluentes ao longo do curso d'água, que introduzem agentes microbiológicos e substâncias químicas no leito do rio².

Considerando as distintas pressões antrópicas exercidas sobre o córrego Ribeirão Preto, os usos indevidos das águas deste manancial pela população do entorno, assim como a importância epidemiológica dos vírus patogênicos de veiculação hídrica, o presente estudo teve como objetivo avaliar a presença de adenovírus e rotavírus em diferentes pontos de amostragem no córrego Ribeirão Preto, SP.

\section{MÉTODOLOGIA}

\section{Local de estudo e amostragem}

O córrego Ribeirão Preto possui $42 \mathrm{~km}$ de extensão e tem sua nascente localizada no município de Cravinhos-SP, percorrendo o município de Ribeirão Preto - SP, até sua confluência no Rio Pardo. Foram definidos 11 pontos de coleta, desde a nascente (Ponto 0) até a foz (Ponto 10) (Figura 1). Realizou-se uma campanha para a coleta de amostras de água nos 11 pontos, no período de janeiro a março de 2015 (estação chuvosa). Amostras de água foram coletadas em frascos estéreis de $2 \mathrm{~L}$ e mantidas sob refrigeração até o momento das análises.

\section{Análise de Adenovírus e Rotavírus}


As amostras de água foram previamente clarificadas para a remoção de resíduos grosseiros por filtração com pré-filtro AP20® (membrana de $45 \mathrm{~mm}$ de diâmetro, Millipore) utilizando o sistema de filtração (Millipore). Posteriormente as amostras foram concentradas utilizando membranas de ultrafiltração (50 kDa - Amicon - Modelo 8050).

O método utilizado para detecção dos vírus foi o teste de ELISA tipo sanduíche (RIDASCREEN $®$ Adenovirus e RIDASCREEN $\AA$ Rotavirus, R-Biopharm), o qual se baseia na detecção de antígenos, utilizando anticorpos monoclonais. A superfície de cada poço da microplaca que vem junto ao teste, é revestido por um anticorpo monoclonal específico para o antígeno. A amostra a ser examinada, é então adicionada no poço da microplaca, juntamente com anticorpos contra o vírus específico (Conjugado 1) para incubação à temperatura ambiente $\left(20-25{ }^{\circ} \mathrm{C}\right)$. Depois de uma etapa de lavagem, um conjugado de anticorpo ligado a uma enzima (Conjugado 2) é adicionado e incubado novamente à temperatura ambiente $\left(20-25^{\circ} \mathrm{C}\right)$. Com a presença do vírus específico na amostra, se formará um complexo de sanduíche, que consiste em anticorpos imobilizados, os antígenos do vírus, e os anticorpos conjugados. Assim, outra etapa de lavagem remove o conjugado não ligado. Em amostras positivas, a adição de um substrato muda a enzima e dessa forma, o cromógeno muda de $\operatorname{cor}^{15}$. A leitura da absorbância (densidade óptica) reflete à concentração de antígeno nas amostras, medida a $450 \mathrm{~nm}$ utilizando um leitor de placas ELISA (Modelo TP-Reader, Thermo Plate, Brasil). Para ambos os vírus, o resultado foi considerado positivo quando a absorbância da amostra foi maior que o valor do cut-off (definido como a absorbância média dos controles negativos mais 0,1 , de acordo com as especificações do fabricante) $)^{15}$.

Figura 1 - Pontos de coleta no Córrego Ribeirão Preto, delimitando esquematicamente o trajeto do curso de água desde a nascente até a confluência com o Rio Pardo. 2015. Fonte: Adaptado de Alves².

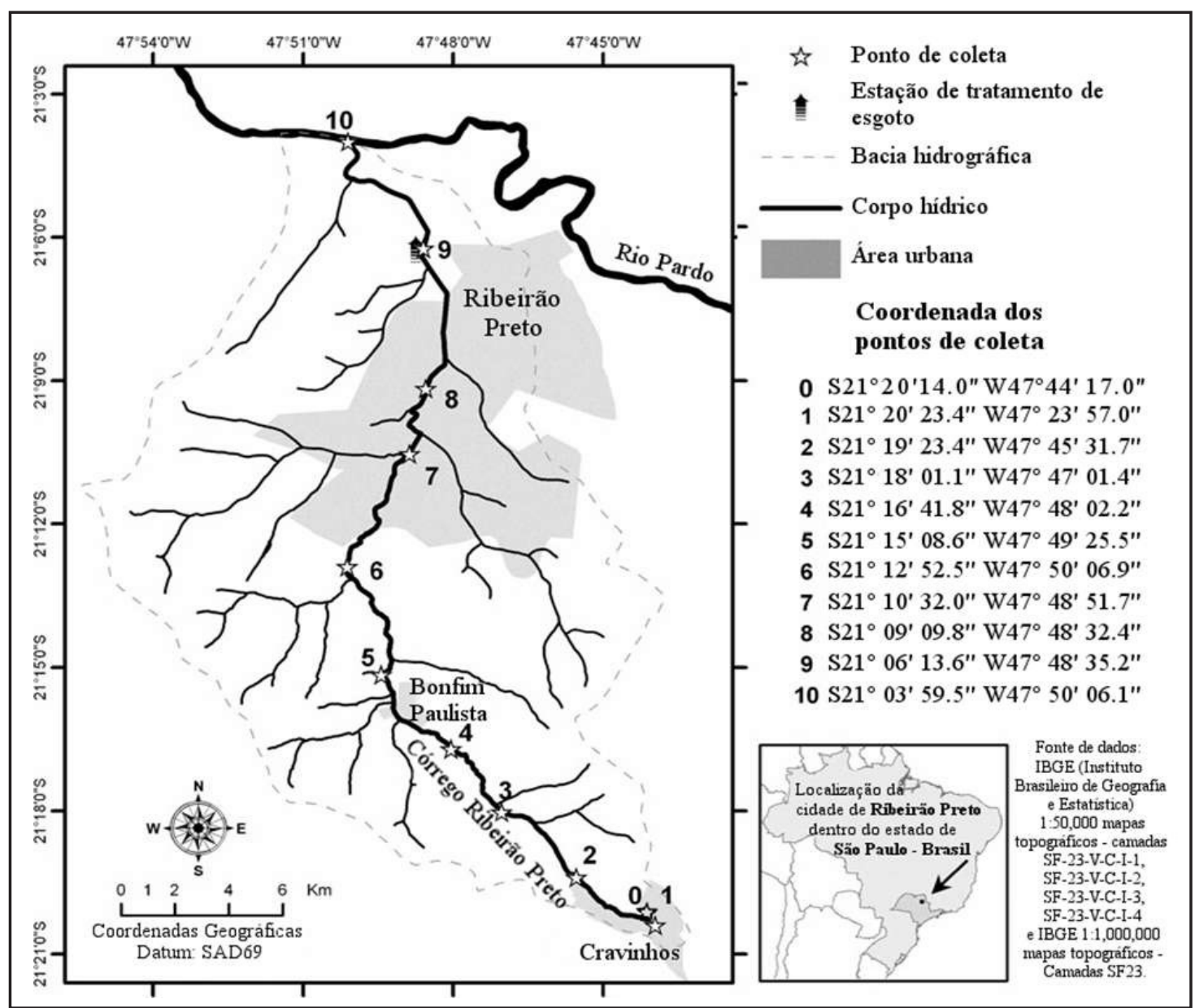




\section{RESULTADOS}

As Figuras 2 e 3 mostram a presença de (pontos 0, 1, 2, 3, 4, 8, 9 e 10) enquanto que antígeno de adenovírus e rotavírus detectada 36\% foram positivas para rotavírus (pontos 0, 1 , em amostras de água coletada no córrego 4 e 9). É possível observar que os pontos 5, 6 e Ribeirão Preto, SP.

7 não apresentam contaminação por nenhum

De acordo com os resultados obtidos $73 \%$ dos vírus estudados, o que corresponde a $27 \%$ das amostras foram positivas para adenovírus das amostras.

Figura 2 - Variação da densidade de antígeno de adenovírus em amostras de água do córrego Ribeirão Preto. Ribeirão Preto, SP. 2015.

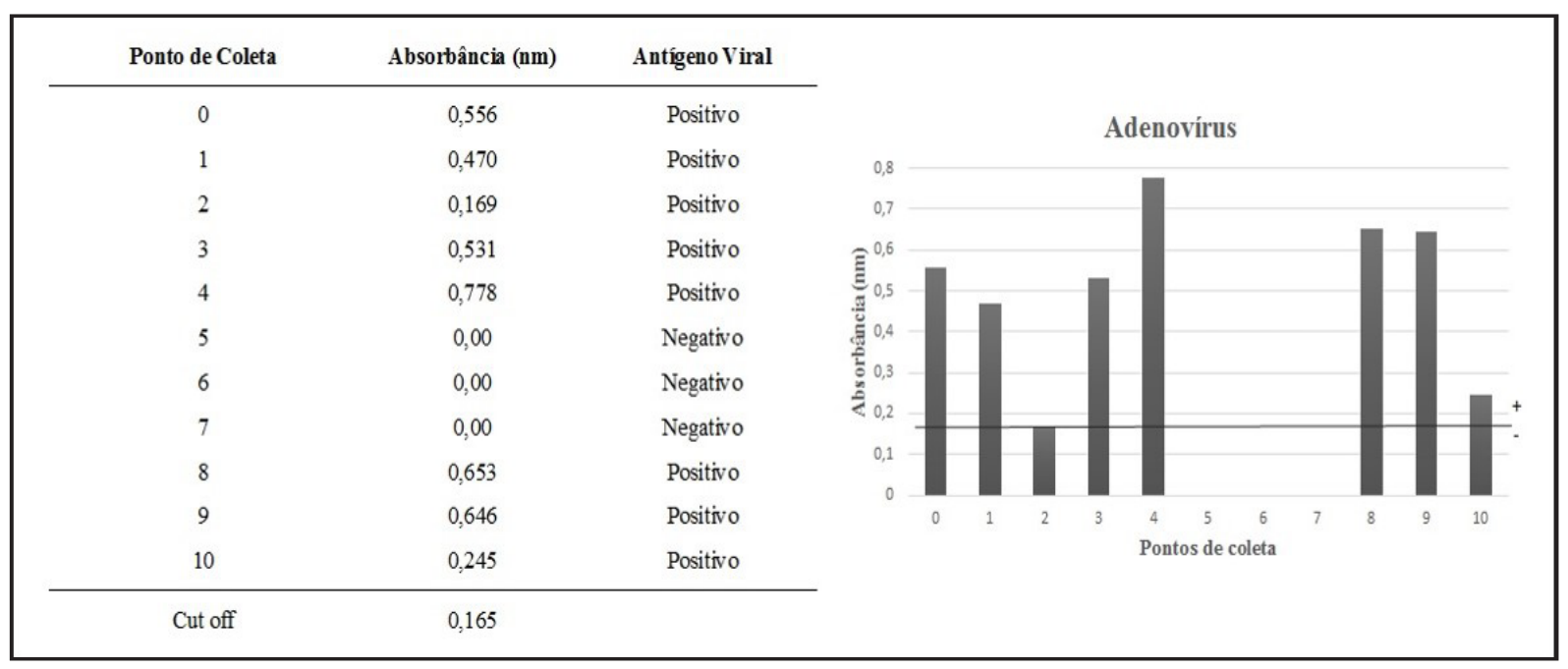

Figura 3 - Variação da densidade de antígeno de rotavírus em amostras de água do córrego Ribeirão Preto. Ribeirão Preto, SP. 2015.

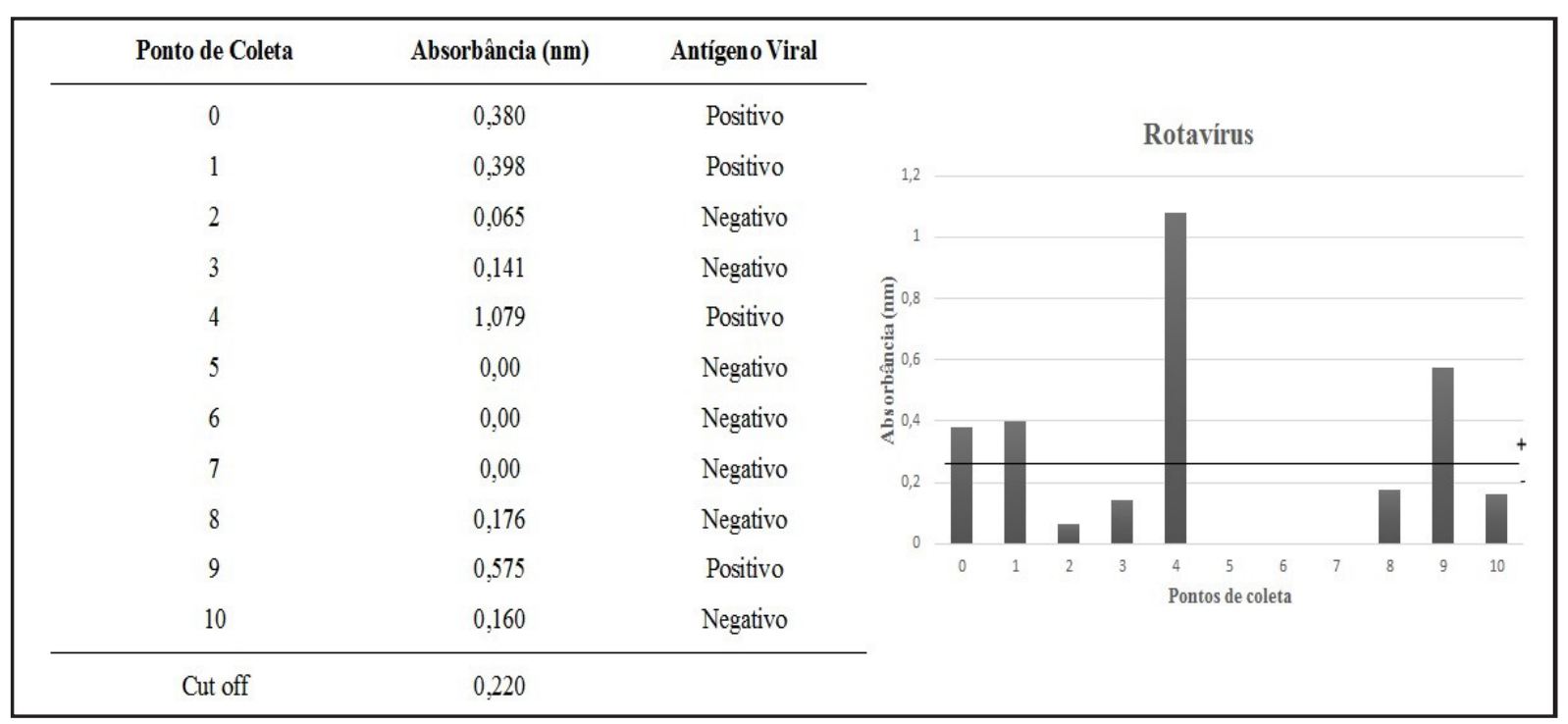




\section{DISCUSSÃo}

Ribeirão Preto é uma cidade amplamente urbanizada localizada na região Nordeste do estado de São Paulo, sendo um dos mais importantes polos regionais do estado. Embora a cidade se destaque no âmbito de saneamento, com capacidade para coletar $100 \%$ do esgoto doméstico e tratar $98 \%$, informações atualizadas revelam que aproximadamente $80 \%$ do esgoto coletado é tratado, sendo que os percentuais restantes são despejados nos corpos de água ${ }^{16,17}$. Além disso, os córregos que cortam a cidade apresentam inúmeras irregularidades, como degradação das matas ciliares, despejo de esgoto doméstico clandestino, além da deposição de resíduos. Este cenário contribui para a contaminação química e microbiológica dos corpos hídricos, o que pode comprometer à saúde das populações no entorno ${ }^{2}$.

Os resultados mostram que adenovírus e rotavírus estão presentes ao longo do córrego Ribeirão Preto evidenciando que o número de amostras com a presença de Adenovírus foi $37 \%$ superior quando comparado ao número de amostras com a presença de rotavírus. A disseminação e concentração do adenovírus verificada no presente estudo pode estar relacionada com sua maior resistência a desinfecção por diferentes sistemas de tratamentos de água e esgoto e às variações extremas de $\mathrm{pH}^{18}$. No mesmo sentido, Prevost et al. ${ }^{11}$ realizaram uma pesquisa de vírus entéricos em águas superficiais do rio Sena, na França, e encontraram um maior número de amostras contaminadas por adenovírus (93\%) do que por rotavírus (57\%).

Ao fazer uma avaliação da presença do adenovírus e rotavírus ao longo do córrego podem ser evidenciadas algumas condições ambientais determinantes para a disseminação desses agentes patogênicos.

Embora o ponto 0 (nascente) esteja localizado em um parque ecológico, as amostras de água do local apresentaram adenovírus e rotavírus, sendo explicado pela presença de animais em seu entorno, especialmente aves e mamíferos transmissores desses agentes ${ }^{19,20}$.

Os pontos 1, 2, 3 e 4, localizados no perímetro urbano, estão sujeitos a maior contaminação por descargas de dejetos humanos consequentes das ligações clandestinas de esgoto na rede pluvial e lançamento de efluentes in natura diretamente em suas águas ${ }^{10,19}$.

À montante do ponto 5, o córrego Ribeirão Preto recebe a água do córrego Limeira, um de seus principais efluentes, e de mais dois córregos de menor aporte ${ }^{19}$. O aumento de volume de água no leito do córrego pode ter contribuído para diluição das partículas virais ou até mesmo para os processos naturais de autodepuração ${ }^{21}$, o que justifica a ausência de antígenos de adenovírus e rotavírus nos pontos 5,6 e 7 .

O ponto 8 se localiza na zona urbana e recebe contribuição das águas do córrego Monte Alegre, Retiro Saudoso e Tanquinho. Tais afluentes se localizam na cidade e dessa forma não recebem efluentes de atividades agropecuárias. Entretanto, estudos e notícias atuais demonstram a contaminação de suas águas, inferindo lançamentos de esgoto in natura bem como falhas na rede de distribuição, o que pode ter contribuído para alta densidade de vírus entéricos encontrados neste ponto ${ }^{22,23,24}$.

Os pontos de coleta 9 e 10 estão localizados à jusante do lançamento de esgoto tratado da estação de tratamento de esgoto (ETE) de Ribeirão Preto. De acordo com a Ambient ${ }^{25}$, a cidade despeja aproximadamente 50 milhões m3/ano de esgoto tratado nas águas do córrego Ribeirão Preto. Dessa forma, é possível que este efluente esteja influenciando os resultados, visto que processos de tratamento de esgoto por lodos ativados não são totalmente eficientes na remoção de adenovírus e rotavírus, corroborando com os resultados encontrado por Tonani et al. ${ }^{9}$.

A presença de adenovírus e rotavírus em amostras ambientais aponta para a necessidade de monitoramento desses patógenos, perante sua significância sanitária, uma vez que, oferecem elevado risco para a saúde pública além de apresentarem uma difícil remoção e inativação por processos convencionais de tratamento de água e esgoto. Cabe destacar que em um estudo recente realizado por Tonani et al. ${ }^{9}$, foi detectado a presença de adenovírus e rotavírus em esgoto bruto e tratado da ETE de Ribeirão Preto, SP., nos alertando para a possível circulação desses patógenos virais 
na população. Cabe destacar que relatos divulgados na imprensa da cidade mostram que a população do município utiliza as águas do córrego Ribeirão Preto para higiene pessoal, lazer e dessedentação de animais colocando a população em contato direto ou indireto à diversos contaminantes ambientais ${ }^{14}$.

Dessa forma, é de indubitável relevância trabalhar frente à adoção de políticas públicas voltadas para a conscientização da população sobre os usos da água, bem como para questões envolvendo saúde e saneamento.

\section{CONCLUSÃO}

Os resultados demonstraram que o córrego Ribeirão Preto apresenta contaminação por adenovírus e rotavírus, o que pode evidenciar o lançamento de efluentes domésticos e agropecuários em suas águas e/ou nas águas de seus afluentes, uma vez que, esses patógenos são eliminados nas fezes de pessoas ou animais infectados.

O saneamento ambiental tem papel essencial no controle e disseminação dos vírus entéricos, dessa forma o monitoramento das condições microbiológicas nos corpos d' água, representam uma ferramenta sanitária relevante.

Além disso, é necessária a implementação de ações de recuperação das águas superficiais em todo o território nacional, visando à preservação ambiental, a garantia de fontes de água e consequentemente a manutenção da qualidade de vida da população.

AGRADECIMENTOS: Ao Programa Institucional de Bolsas de Iniciação Científica (PIBIC), pela concessão de bolsa de iniciação científica e à Fundação de Amparo à Pesquisa do Estado de São Paulo (FAPESP) pelo auxílio regular (Processo № 2013/07238-2).

\section{REFERÊNCIAS}

1. Ali MH, Abustan I, Rahman MA, Haque AAM. Sustainability of Groundwater Resources in the North-Eastern Region of Bangladesh. Water Resour Magane 2011; 26:623-641.

2. Alves RIS, Cardoso OO, Tonani KAA, Julião F. C.; Trevillato TMB, Segura-Munoz SI. Water quality of the Ribeirão Preto Stream, a watercourse under anthropogenic influence in the southeast of Brazil. Environ Monit Assess 2013; 185: 1151-1161.

3. Purandara BK, Varadarajan N, Venkatesh B, Choubey VK. Surface water quality evaluation and modeling of Ghataprabha River, Karnataka, India. Environ Monit Assess 2012; 184(3): 1371-1378.

4. World Health Organization (WHO). 2015. [acesso 2015 ago 19]. Disponível em: http://www.who.int/water_sanitation_health/ takingcharge.html

5. Bosch A, Guix S, Sano D, Pintó RM. New tools for the study and direct surveillance of viral pathogens in water. Curr Opin Biotech 2008; 19:295-301.

6. Sinclair RG, Jones EL, Gerba CP. Viruses in recreational water-borne disease outbreaks: a review. J Appl Microbiol 2009; 107(6): 1769-1780.

7. Yezli SJ, Otter, J. Minimum infective dose of the major human respiratory and enteric viruses transmitted through food and the environment. Food Environ Virol 2011; 3: 1-30.

8. Prado T, Miagostovich MP. Virologia ambiental e saneamento no Brasil: uma revisão narrativa. Cad. Saúde Pública 2014; 30(7): 1367-1378.

9. Tonani KAA, Padula JÁ, Julião FC, Fregonesi BM, Alves RIS, Sampaio C.F, Beda CF, Hachich EM, Segura-Muñoz SI. Persistence of Giardia, Cryptosporidium, Rotavirus and Adenovirus in Treated Sewage in São Paulo State, Brazil. J Parasitol 2013; 99: $1144-1147$.

10. Vieira CB, Mendes ACO, Oliveira JM, Gaspar AMC, Leite JPG, Miagostovich MP. Vírus Entéricos na Lagoa Rodrigo de Freitas. Oecologia Australis 2012; 16(3): 540-565.

11. Prevost B, Lucas FS, Gonçalves A, Richard F, Moulin L, Wurtzer S. Large scale survey of enteric viruses in river and waste water underlines the health status of the local population. Environ Int 2015; 79:42-50.

12. Fongaro G, Nascimento MA, Rigotto C, Ritterbush G, Silva AD'A, Esteves PA, Barardi CRM. Evaluation and molecular characterization of human adenovirus in drinking water supplies: viral integrity and viability assays. Virol J 2013; 10:01-09.

13. Instituto de Pesquisas Tecnológicas (IPT). Relatório número 40.670 "Diagnóstico da atuação atual dos recursos hídricos e estabelecimentos de diretrizes técnicas para a elaboração do plano de bacia hidrográfica do Pardo - Relatório Final. [acesso 2015 ago 25]. Disponível em: 
http://www.sigrh.sp.gov.br/public/uploads/documents/7271/relatorio_zero_cbh_pardo.pdf

14. Quartier S. Vida sem trégua, na Baixada 24 horas. A Cidade, Ribeirão Preto, 7 nov. 2009. Especial, p. A16.

15. Microgen Bioproducts Ltda. Manual de procedimentos. REF. M481 Adenoscreen ${ }^{\circledR}$ EIA/M480 Rotascreen $®$ EIA. Camberley, Surrey GU15 3DT, 2014.

16. Trata Brasil. Ranking de Saneamento. 2013. [acesso 2015 Ago 20]. Disponível em: http://www.tratabrasil.org.br/datafiles/estudos/ ranking/tabela-100cidades-2015.pdf

17. Justiça dá prazo para Daerp acabar com esgoto irregular em Ribeirão. Jornal A Cidade; 2015 Jul 02. [acesso 2015 ago 20]. Disponível em:

http://www.viaeptv.com/noticias/noticias_internaNOT.aspx?idnoticia=1077482

8. Mena KD, Gerba CP. Waterborne Adenovirus. Rev Environ Contam Toxicol 2009; 198: 133-167.

19. Prefeitura Municipal de Cravinhos. Playground no Parque Ecológico tem atraído às crianças. [acesso 2015 ago 03]. Disponível em: http://www.cravinhos.sp.gov.br/conteudo/playground-no-parque-ecologico-tem-atraido-as-criancas.html

20. Companhia de Tecnologia e Saneamento Ambiental (CETESB). Análises Microbiológicas de Amostras Ambientais. São Paulo: CETESB; 2009.

21. Nunes TCG, Glória Menezes G, Batista SLG, Oliveira, VDPS. Monitoramento da qualidade da água do rio Paraíba do Sul na UPEA. 4․ Seminário sobre Gestão de Recursos Hídricos e 5º́órum do Observatório Ambiental 2014 Out 28-30; Campos dos Goytacazes, Rio de Janeiro: Essentia Editora; 2014.

22. Kamada MDL, Lucca GM Lucca JV. Utilização dos macroinvertebrados bentônicos como indicadores da qualidade da água no Córrego Retiro Saudoso em Ribeirão Preto-SP. In: VIII Fórum Ambiental da Alta Paulista; 2012; Tupã. p. 250-261.

23. Grieco AA. Diagnóstico espacial e sazonal de condições físico-químicas e microbiológicas do Córrego Tanquinho, Ribeirão PretoSP [Trabalho de Conclusão de Curso]. Ribeirão Preto (SP): Universidade de São Paulo, Ribeirão Preto; 2014.

24. Pioli J. Moradores da Zona Norte reclamam de esgoto em Córrego Tanquinho. Jornal A Cidade 2015 Mai 13.

25. Ambient. Evolução do volume de esgoto tratado no município de Ribeirão Preto-Período: 2001 até 2014 m3/ano. Dados técnicos. [acesso 2015 ago 27]. Disponível em: http://www.ambient.com.br/estacoes/dados-tecnicos/.

Recebido em janeiro de 2016. Aprovado em novembro de 2016. 